\title{
Molecular Reconstruction of mGluR5a-Mediated Endocannabinoid Signaling Cascade in Single Rat Sympathetic Neurons
}

\author{
Yu-Jin Won, Henry L. Puhl III, and Stephen R. Ikeda \\ Section on Transmitter Signaling, Laboratory of Molecular Physiology, National Institute on Alcohol Abuse and Alcoholism, National Institutes of Health, \\ Bethesda, Maryland 20892-9411
}

\begin{abstract}
Endocannabinoids (eCB) such as 2-arachidonylglycerol (2-AG) are lipid metabolites that are synthesized in a postsynaptic neurons and act upon $\mathrm{CB}_{1}$ cannabinoid receptors $\left(\mathrm{CB}_{1} \mathrm{R}\right)$ in presynaptic nerve terminals. This retrograde transmission underlies several forms of short and long term synaptic plasticity within the CNS. Here, we constructed a model system based on isolated rat sympathetic neurons, in which an eCB signaling cascade could be studied in a reduced, spatially compact, and genetically malleable system. We constructed a complete $\mathrm{eCB}$ production/mobilization pathway by sequential addition of molecular components. Heterologous expression of four components was required for eCB production and detection: metabotropic glutamate receptor $5 a$ (mGluR5a), Homer $2 b$, diacylglycerol lipase $\alpha$, and $\mathrm{CB}_{1} \mathrm{R}$. In these neurons, application of $\mathrm{L}$-glutamate produced voltage-dependent modulation of $\mathrm{N}$-type $\mathrm{Ca}^{2+}$ channels mediated by activation of $\mathrm{CB}_{1} \mathrm{R}$. Using both molecular dissection and pharmacological agents, we provide evidence that activation of mGluR5a results in rapid enzymatic production of 2-AG followed by activation of $\mathrm{CB}_{1} \mathrm{R}$. These experiments define the critical elements required to recapitulate retrograde $\mathrm{eCB}$ production and signaling in a single peripheral neuron. Moreover, production/mobilization of eCB can be detected on a physiologically relevant time scale using electrophysiological techniques. The system provides a platform for testing candidate molecules underlying facilitation of eCB transport across the plasma membrane.
\end{abstract}

\section{Introduction}

Endocannabinoids (eCB) are lipid metabolites that suppress neurotransmitter release at excitatory and inhibitory synapses by serving as agonist for presynaptic $\mathrm{CB}_{1}$ cannabinoid receptors $\left(\mathrm{CB}_{1} \mathrm{R}\right)$. The eCBs are acutely generated ("on-demand") in the postsynaptic neurons following a stimulus and release is believed to occur via passive diffusion through the plasma membrane or facilitated by as yet unidentified mechanisms. The direction of chemical transmission is opposite to fast synaptic transmission and hence eCBs are termed retrograde messengers. Both transient and long-lasting forms of synaptic plasticity are induced by eCB retrograde transmission (Chevaleyre et al., 2006; Lovinger, 2008; Kano et al., 2009).

These characteristics, while interesting, conspire to make the study of neuronal eCB release mechanisms difficult. In particular, the experimental readout for eCB release, depression of synaptic transmission, is highly nonlinear, dependent on numerous presynaptic and postsynaptic elements, and incompletely understood (Xu et al., 2007). We thus sought to construct a model

Received May 12, 2009; revised Sept. 23, 2009; accepted Sept. 23, 2009.

This research was supported by the Intramural Research Program of the National Institutes of Health-National Institute on Alcohol Abuse and Alcoholism. We are grateful to Dr. David M. Lovinger for many helpful discussions and reading an earlier draft of this manuscript.

Correspondence should be addressed to Dr. Stephen R. Ikeda, Laboratory of Molecular Physiology, National Institutes of Health-National Institute on Alcohol Abuse and Alcoholism, Fishers Lane 5625, Room TS-11, MSC 9411 , Bethesda MD, $20892-9411$ (for regular mail), Rockville, MD 20852 (for express mail). E-mail:sikeda@mail.nih.gov. DOI:10.1523/JNEUROSCI.2244-09.2009

Copyright $\odot 2009$ Society for Neuroscience ～0270-6474/09/2913603-10\$15.00/0 neuronal system in which eCB production and $\mathrm{CB}_{1} \mathrm{R}$ activation could be studied in a reduced, spatially compact, and genetically malleable system. Of the two best characterized eCBs, N-arachidonoylethanolamide (anandamide) and 2-arachidonoylglycerol (2AG), we focused on the latter. The canonical 2-AG synthetic pathway (Kano et al., 2009) starts with hydrolysis of plasma membrane phosphatidylinositol 4,5-bisphosphate $\left(\mathrm{PIP}_{2}\right)$ by phospholipase $C$ (PLC) following activation of a $G_{q / 11}$-coupled GPCR. The resulting diacylglycerol (DAG) is further hydrolyzed by an $s n$ - 1 specific diacylglycerol lipase, DAGL $\alpha$, to a fatty acid and 2-AG. Finally, 2-AG is hydrolyzed to arachidonic acid and glycerol by monoacylglycerol lipase (MAGL) and possibly other enzymes (Blankman et al., 2007).

We chose rat sympathetic neurons as a surrogate into which identified molecular components could be added to recapitulate eCB retrograde signaling within a single neuron. Previously, we demonstrated that $\mathrm{CB}_{1} \mathrm{R}$ heterologously expressed in sympathetic neurons produced voltage-dependent modulation of natively expressed $\mathrm{N}$-type $\mathrm{Ca}^{2+}\left(\mathrm{Ca}_{\mathrm{V}} 2.2\right)$ channels following extracellular application of 2-AG (Guo and Ikeda, 2004). This system provides a robust detector for 2-AG release that is relevant to events occurring within the less accessible presynaptic nerve terminal. In this study, we sought to recapitulate endogenous mobilization of $2-A G$ and $\mathrm{CB}_{1} \mathrm{R}$ activation in a single neuron. We based our system on a short term form of synaptic depression in which postsynaptic activation of $\mathrm{G}_{\mathrm{q} / 11}$-coupled receptors such as group I metabotropic glutamate receptors (mGluRs) produce eCB-mediated retrograde suppression without a requirement for 
internal $\left[\mathrm{Ca}^{2+}\right]$ elevation (Kano et al., 2009). Expression of mGluR 5a (mGluR5a), Homer 2b, DAGL $\alpha$, and $\mathrm{CB}_{1}$ R in sympathetic neurons was sufficient to produce robust modulation of $\mathrm{N}$-type $\mathrm{Ca}^{2+}$ channels following L-glutamate application. The characteristics of the response were consistent with generation of 2-AG following glutamate application, transport into or through the plasma membrane, and activation of $\mathrm{CB}_{1} \mathrm{R}$. Recapitulation of retrograde $\mathrm{eCB}$ signaling in a single neuron provides an experimental platform to further refine mechanisms underlying eCB signaling cascades.

\section{Materials and Methods}

Cloning. The open reading frame for human DAG Lipase $\alpha$ (accession \#AB014559) was amplified by the PCR from whole brain cDNA (Clontech) with Phusion polymerase (New England Biolabs). PCR primers incorporated 5' MluI and 3' NotI restriction enzyme sites and the product was cloned into the MluI/NotI sites of the mammalian expression vector pCI (Promega). This plasmid was used as a PCR template for the construction of a C-terminal fluorescently tagged protein (DAV). The restriction enzyme sites XhoI $\left(5^{\prime}\right)$ and HindIII $\left(3^{\prime}\right)$ were added and the PCR product was cloned into these sites in the vector Venus-N1. Deletions of residues M1 to G189 (N-terminal deletion) or Q190 to R1042 (C-terminal deletion) from the full-length DAG lipase $\alpha$ Venus fusion construct was accomplished using the QuikChange site directed mutagenesis kit (Stratagene/Agilent Technologies).

Preparation of superior cervical ganglion neurons. All of the animal studies were conducted according to the National Institutes of Health's Guidelines for Animal Care and Use. Single neurons of superior cervical ganglion (SCG) from adult male Wister rats (200-250 g) were enzymatically dissociated as described previously (Ikeda, 2004; Ikeda and Jeong, 2004). Animals were anesthetized by $\mathrm{CO}_{2}$ inhalation and subsequently decapitated before dissection. The SCG were removed bilaterally, desheathed, cut into small pieces, and incubated in the modified Earles' balanced salt solution (EBSS) containing $2 \mathrm{mg} / \mathrm{ml}$ collagenase CLS4 (Worthington Biochemical), $0.6 \mathrm{mg} / \mathrm{ml}$ trypsin TRL (Worthington Biochemical), and $0.05 \mathrm{mg} / \mathrm{ml}$ DNase I (Sigma-Aldrich) at $35.5^{\circ} \mathrm{C}$ for 60 min. The EBSS was modified by adding $3.6 \mathrm{~g} / \mathrm{L}$ glucose and $10 \mathrm{~mm}$ HEPES. After incubation, neurons were dissociated by vigorous shaking of the flask. The dissociated cells were washed twice, transferred to minimum essential medium (MEM) containing 10\% fetal bovine serum and $1 \%$ penicillin-streptomycin (all from Invitrogen), plated on poly-Llysine (Sigma-Aldrich) coated tissue culture dishes and maintained in a humidified $95 \%$ air $/ 5 \% \mathrm{CO}_{2}$ incubator at $37^{\circ} \mathrm{C}$.

Intranuclear injection of $c D N A s$. Vectors encoding particular proteins were directly injected into the nucleus of SCG neurons as described previously (Ikeda, 2004; Ikeda and Jeong, 2004). Briefly, injection of cDNA was performed with an Eppendorf FemtoJet microinjector and $5171 \mathrm{mi}-$ cromanipulator (Eppendorf) using injection pressure and duration of $160-180 \mathrm{hPa}$ and $0.3 \mathrm{~s}$, respectively. Vectors containing inserts coding for human $\mathrm{CB}_{1} \mathrm{R}$ (NM 016083) (pcDNA3.1; Invitrogen), rat mGluR5a, human Homer 2b (both in pRK5; Genentech), and human DAG lipase $\alpha$ (AB014559; cloned into Venus-N1) were diluted in TE buffer $(10 \mathrm{~mm}$ Tris, 1 mm EDTA, pH 7.4) to final concentrations of 10, 100, 100, and 10 $\mathrm{ng} / \mu \mathrm{l}$, respectively. Each cDNA was injected alone or in combinations as dictated by the experiment. Neurons were coinjected with "enhanced" green fluorescent protein cDNA (5 ng/ $\mu$; pEGFP-N1; BD Biosciences Clontech) to identify successfully injected neurons. Following injection, the neurons were incubated overnight at $37^{\circ} \mathrm{C}$. Whole-cell patch-clamp experiments were performed the following day.

Electrophysiological recording. $\mathrm{Ca}^{2+}$ channel currents $\left(I_{\mathrm{Ca}}\right)$ were recorded using the whole-cell patch-clamp technique (Hamill et al., 1981) as described previously (Guo and Ikeda, 2004). Patch electrodes were fabricated from a premium custom 8520 patch glass $(1.65 \mathrm{~mm}$ outer diameter, $1.28 \mathrm{~mm}$ inner diameter; Warner Instruments) using a Model P-97 micropipette puller (Sutter Instrument). The patch electrodes were coated with Sylgard 184 (Dow Corning) and fire-polished to a final resistance of $\sim 1.5-2 \mathrm{M} \Omega$ when filled with the pipette solution described below. The bath was grounded by an $\mathrm{Ag} / \mathrm{AgCl}$ pellet connected via a $0.15 \mathrm{M}$
$\mathrm{NaCl} /$ agar bridge. The cell membrane capacitance was cancelled and series resistance was compensated ( $>85 \%$ for both prediction and compensation; lag set to $10 \mu \mathrm{s}$ ) with the patch-clamp amplifier (Axopatch 200B amplifier; Molecular Devices). Voltage protocol generation and data acquisition were performed using custom-designed software (S5) on a Macintosh G4 computer (Apple Computer) equipped with an ITC-18 data acquisition interface (InstruTECH Corporation). Current traces were filtered at $2 \mathrm{kHz}(-3 \mathrm{~dB})$ using a four-pole low-pass Bessel filter, digitized at $10 \mathrm{kHz}$ with a 16-bit analog-to-digital converter in the ITC-18 data acquisition interface, and stored on the computer for later analyses. All drugs and control solution were applied to single neurons via a custom-designed gravity-driven perfusion system. A fused silica gas chromatography column at the end of the perfusion system was connected to seven parallel columns of the same diameter. Drug application was started by switching the control external solution to a drug solution to avoid flow-induced artifact until the desired test solution was applied. All recordings were performed at room temperature $\left(21-24^{\circ} \mathrm{C}\right)$.

Solutions and chemicals. For recording $I_{\mathrm{Ca}}$, patch pipettes were filled with an internal solution containing $120 \mathrm{~mm} \mathrm{~N}$-methyl-D-glucamine, 20 mM tetraethylammonium hydroxide (TEA-OH), 11 mM EGTA, 10 mM HEPES, $1 \mathrm{~mm} \mathrm{CaCl}_{2}$, $10 \mathrm{~mm} \mathrm{HCl}, 4 \mathrm{~mm} \mathrm{MgATP}, 0.1 \mathrm{~mm} \mathrm{Na}_{2} \mathrm{GTP}$ and 14 $\mathrm{mm}$ Tris creatine phosphate ( $\mathrm{pH} 7.2$, with methanesulfonic acid). External recording solution consisted of $140 \mathrm{~mm}$ methanesulfonic acid, 145 mM TEA-OH, 10 mm HEPES, 10 mm glucose, $10 \mathrm{~mm} \mathrm{CaCl}_{2}$ and $0.3 \mu \mathrm{M}$ tetrodotoxin ( $\mathrm{pH} 7.4$ with TEA-OH). 2-AG was purchased from Tocris Bioscience; SR141716A [5-(4-chlorophenyl)-1-(2,4-dichloro-phenyl)4-methyl- $N$-(piperidin-1-yl)- $1 \mathrm{H}$-pyrazole-3-carbox-amide), Rimonabant] was a gift of the Sanofi Research Center (Montpellier, France); L-glutamic acid hydrochloride and tetrahydrolipstatin (THL, Orlistat) were purchased from Sigma-Aldrich; Bordetella pertussis holotoxin (PTX) was purchased from List Biological Laboratories; tetrodotoxin was purchased from Alomone Laboratories; 1,2-Dioctanoylglycerol $\left(\mathrm{DiC}_{8}\right)-\mathrm{PIP}_{2}$ was purchased from Echelon Biosciences. Stock solutions of 2-AG, SR141716A, and THL were prepared in dimethyl sulfoxide (DMSO). $\left(\mathrm{DiC}_{8}\right)-\mathrm{PIP}_{2}$ was prepared in the internal solution. Fatty acidfree bovine serum albumin (BSA) was added to all external solution at 0.5 $\mathrm{mg} / \mathrm{ml}$ to prevent the lipid-soluble drugs from sticking to tubing. All drugs were diluted to the final concentrations from stock solutions on the day of the experiment.

Data analysis and statistics. Current traces were analyzed using Igor Pro version 6 (WaveMetrics) and statistical tests performed with Prism 5 for Mac OS X (GraphPad Software). All data are expressed as mean \pm SEM unless otherwise stated. The percentage inhibition (\%) was determined using the equation $\left(I_{\text {con }}-I_{\text {drug }}\right) / I_{\text {con }} \times 100$, where $I_{\text {con }}$ and $I_{\text {drug }}$ are the $I_{\mathrm{Ca}}$ amplitudes before and after drug application, respectively. Statistical significance between two groups was determined using paired or unpaired Student's $t$ tests, as appropriate. Multiple comparisons were performed with a one-way ANOVA followed by Dunnett's or Tukey post hoc tests as indicated. $p<0.05$ was considered significant.

Single-cell RT-PCR. Single-cell RT-PCR was performed using the OneStep RT-PCR kit following the manufacturer's protocol (QIAGEN). Briefly, a dissociated SCG neuron was collected by suction into a firepolished glass capillary filled with DEPC-treated water $(<3 \mu \mathrm{l})$. The pipette tip containing the single cell was broken inside a PCR tube containing components for both reverse transcription and PCR amplification. Forward and reverse primer sequences were targeted to different exons allowing discrimination of products amplified from mRNA versus genomic DNA. The following rat DAG lipase $\alpha$ primers were used: set 1 (365 bp); exon 3 forward (bases 155-175) 5'-CCCTGAACCTGGTGGACCACG-3', with exon 5 reverse (bases 519-498) 5'-CCTCCTCTTGGTGGCTCTCAGC-3' ${ }^{\prime}$ set 2 (517 bp); exon 19 forward (bases 2131-2150) 5'-GCTCTGGAGCTGCCTGCCAC-3', with exon 20 reverse (bases 2647-2627) 5' -CTGCCTCCTCCTCGTCATTGG-3'. Specificity of primers was tested with total RNA prepared from whole SCG. External solution without cells collected from same dish served as the negative control. The first-strand cDNA synthesis reaction was performed at $50^{\circ} \mathrm{C}$ for $30 \mathrm{~min}$. The samples were then heated at $95^{\circ} \mathrm{C}$ for 15 min to inactivate reverse transcriptase and activate HotStarTaq DNA Polymerase. The PCR was performed for 40 cycles consisting of $94^{\circ} \mathrm{C}$ for 
A
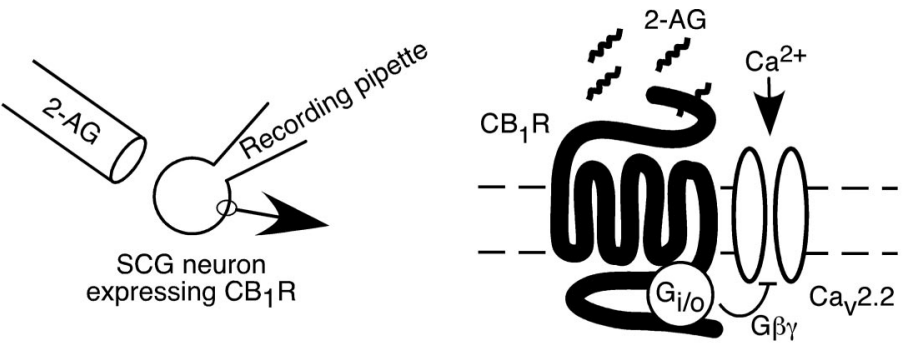

B
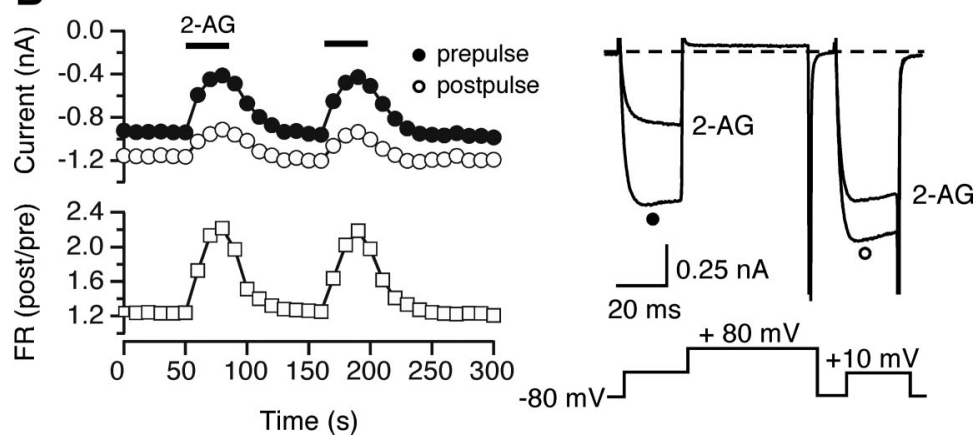

Figure 1. Modulation of $\mathrm{Ca}^{2+}$ current by 2-AG in rat $S C G$ neurons expressing $C B_{1} R s . A, A$ schematic representation for $G_{i / 0^{-}}$ mediated $I_{C a}$ inhibition via $\mathrm{CB}_{1} R$ activation. Left, The diagram depicts the whole-cell patch-clamping mode from an SCG neuron previously injected with $C_{1} R$ cDNA. Right, Externally applied 2-AG from a drug perfusion system activates $G_{1 / 0}$-protein coupled $\mathrm{CB}_{1}$ R and inhibits $I_{\mathrm{C}_{\mathrm{C}}}$ by $G \beta \gamma \cdot \boldsymbol{B}$, Time courses of $I_{\mathrm{Ca}_{\mathrm{a}}}$ (left) and superimposed current traces (right) evoked with the voltage protocol illustrated (right bottom) from $\mathrm{CB}_{1} R$ injected SCG neurons. The $I_{\mathrm{Ca}_{\mathrm{a}}}$ amplitude generated by the prepulse (filled circles) and postpulse (open circles) are plotted. FR was calculated as the ratio of the post-pulse to prepulse $I_{\text {Ca }}$ amplitude (open squares). The horizontal bars indicate the duration of 2-AG application.

$30 \mathrm{~s}, 59^{\circ} \mathrm{C}$ for $30 \mathrm{~s}$, and $72^{\circ} \mathrm{C}$ for $1 \mathrm{~min} 30 \mathrm{~s}$. The final extension was performed at $72^{\circ} \mathrm{C}$ for $5 \mathrm{~min}$. As an internal reference, $\beta$-actin mRNA was amplified concurrently (i.e., multiplexed) with the following primer set (982 bp product): exon 1 forward (bases 30-51) 5'-CGACAACGGCTCCGGCATGTGC-3' with exon 5 reverse (bases 1011-991) $5^{\prime}$ GTACTTGCGCTCAGGAGGAGC-3'. The PCR products were analyzed by agarose gel electrophoresis and visualized using SYBR safe DNA gel stain (Invitrogen).

\section{Results}

Modulation of $\mathrm{Ca}^{2+}$ current by $2-\mathrm{AG}$ via $\mathrm{CB}_{1}$ receptor

To construct an eCB signaling cascade within a single neuron, we used a previously characterized system in which $\mathrm{CB}_{1}$ Rs were heterologously expressed in dissociated rat sympathetic neurons (Guo and Ikeda, 2004). The expressed $\mathrm{CB}_{1} \mathrm{R}$ efficiently couple to endogenous PTX-sensitive G-proteins and modulate natively expressed $\mathrm{N}$-type $\left(\mathrm{Ca}_{\mathrm{V}} 2.2\right) \mathrm{Ca}^{2+}$ channels following external application of 2-AG (Fig. 1A). Previous studies have established that SCG neurons do not natively express functional $\mathrm{CB}_{1} \mathrm{R}$ (Guo and Ikeda, 2004). Figure $1 B$ illustrates $I_{\mathrm{Ca}}$ time courses and traces recorded from SCG neurons $\sim 18-24 \mathrm{~h}$ following intranuclear injection of cDNA encoding $\mathrm{CB}_{1} \mathrm{R} . I_{\mathrm{Ca}}$ was evoked at $0.1 \mathrm{~Hz}$ with a double-pulse voltage protocol (Elmslie et al., 1990) consisting of a test pulse to $+10 \mathrm{mV}$ (the "prepulse"), a strong depolarizing conditioning pulse to $+80 \mathrm{mV}$, and second identical test pulse to $+10 \mathrm{mV}$ (the "postpulse"). Prepulse amplitude (closed circles), postpulse amplitude (open circles) and the facilitation ratio (FR, open squares), defined as the ratio of the postpulse to prepulse amplitude (post/pre), were plotted as illustrated in Figure $1 B$ (left). An increase in FR indicates voltage-dependent $\mathrm{Ca}^{2+}$ channel inhibition mediated by G-protein $\beta \gamma$ subunits (Ikeda, 1991, 1996; Ikeda and Dunlap, 1999). As previously shown (Guo and Ikeda, 2004), application of 2-AG produced three characteristics of voltage-dependent modulation: (1) a slowing of $I_{\mathrm{Ca}}$ activation (kinetic slowing) in the prepulse test current, (2) $I_{\mathrm{Ca}}$ inhibition and kinetic slowing relieved by a depolarizing conditioning pulse, and ( 3 ) a robust $(\geq 2)$ increase in FR. Figure $1 B$ also shows that 2-AG produced a rapid inhibition of $I_{\mathrm{Ca}}$ amplitude, which usually recovered within $60 \mathrm{~s}$ following termination of $2-\mathrm{AG}$ application. Furthermore, repeated applications of 2-AG display a consistent response without evidence of tachyphylaxis (Fig. $1 B$, left).

\section{Construction of an eCB synthesis/detection system within single sympathetic neurons}

Upon this foundation, we designed a 2-AG biosynthesis, transport, and detection system within a single neuron. Although several pathways for eCB production in postsynaptic neurons have been proposed (Wang and Ueda, 2009), we opted to mimic a pathway in which activation of mGluR5 results in eCB production. The proposed events underlying mGluR5amediated 2-AG generation are shown in Figure $2 A$ along with a system for detecting 2-AG release ( $I_{\mathrm{Ca}}$ modulation by $\left.\mathrm{CB}_{1} \mathrm{R}\right)$. Briefly, activation of mGluR5a by an agonist (e.g., L-glutamate) stimulates PLC $\beta$ via $\mathrm{G} \alpha_{\mathrm{q}}$-GTP (and possibly G $\beta \gamma$ and increased $\left[\mathrm{Ca}^{2+}\right]_{\mathrm{i}}$ ). Diacylglycerol, arising from $\mathrm{PIP}_{2}$ hydrolysis, serves as substrate for DAGL $\alpha$ thereby generating 2-AG. Subsequently, transport of 2-AG, via indeterminate mechanisms, results in $\mathrm{CB}_{1} \mathrm{R}$ activation, stimulation of $\mathrm{G}_{\mathrm{i} / \mathrm{o}}$, and modulation of $\mathrm{N}$-type channels via $\mathrm{G} \beta \gamma$ (Herlitze et al., 1996; Ikeda, 1996). Several components of the system, $\mathrm{G} \alpha_{\mathrm{q}}, \mathrm{G} \alpha_{\mathrm{i} / \mathrm{o}}, \mathrm{G} \beta \gamma$, and PLC $\beta$, are natively expressed in SCG neurons (Delmas et al., 1998; Haley et al., 2000; Kammermeier et al., 2003; Margas et al., 2008) along with the N-type voltagegated $\mathrm{Ca}^{2+}$ channel subunits (Lin et al., 1996, 1997), thus decreasing the number of components requiring heterologous expression.

For $I_{\mathrm{Ca}}$ modulation to be used as a monitor for $\mathrm{CB}_{1} \mathrm{R}$ activation, direct mGluR5a-mediated inhibition of N-type $\mathrm{Ca}^{2+}$ channels requires suppression. As shown in Figure $2 B$, heterologous expression of mGluR5a in rat SCG neurons results in inhibition of N-type $\mathrm{Ca}^{2+}$ channels following L-glutamate $(100 \mu \mathrm{M})$ application that faded during continued agonist exposure. Previous studies demonstrated that group I mGluRs produce a mixture of voltagedependent and -independent $\mathrm{Ca}^{2+}$ channel inhibition using both $\mathrm{G}_{\mathrm{i} / \mathrm{o}}$ and $\mathrm{G}_{\mathrm{q} / 11}$ signaling pathways (Kammermeier and Ikeda, 1999). The mixed inhibitory pathway results in $I_{\mathrm{Ca}}$ modulation that exhibits relief of inhibition by a depolarizing conditioning pulse but to a lesser extent than a $\mathrm{G}_{\mathrm{i} / \mathrm{o}}$-mediated voltage-dependent response (compare Figs. $2 B$ and $1 A$ ) (Kammermeier and Ikeda, 1999). To suppress direct mGluR5a modulation of $I_{\mathrm{Ca}}$, we coexpressed the postsynaptic scaffolding protein Homer $2 \mathrm{~b}$ (Fig. $2 C$ ). In agreement with previous studies (Kammermeier et al., 2000), Homer 2b expression greatly attenuated mGluR5amediated prepulse $I_{\mathrm{Ca}}$ inhibition $(9.0 \pm 1.9 \%, n=12)$ when compared with mGlu5a expression alone $(49.8 \pm 3.4 \%, n=$ 14). The mechanism underlying this phenomenon does not appear to arise from altered mGluR5a surface expression or 
A eCB signaling system

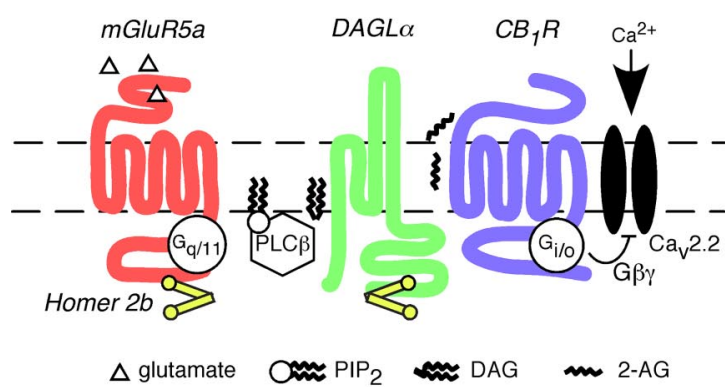

D mGluR5a/Homer $2 \mathrm{~b} / \mathrm{CB}_{1} \mathrm{R}$
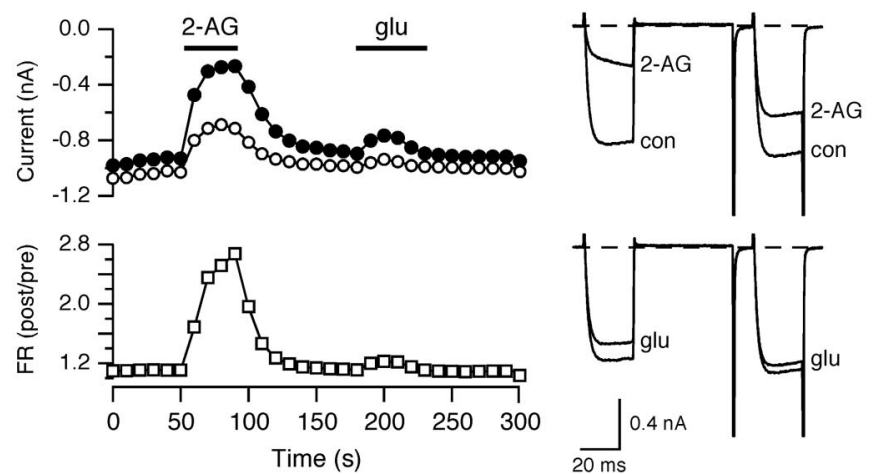

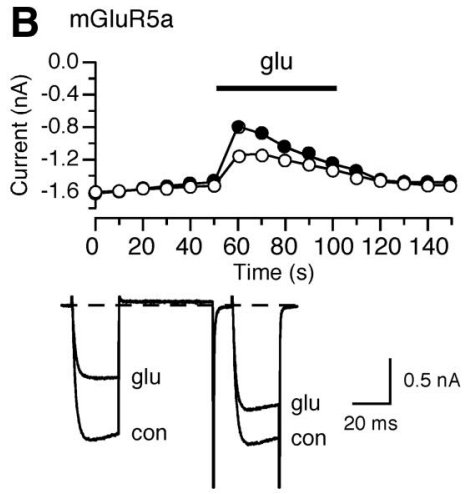

E mGluR5a/Homer 2b/DAGL $\alpha / \mathrm{CB}_{1} \mathrm{R}$
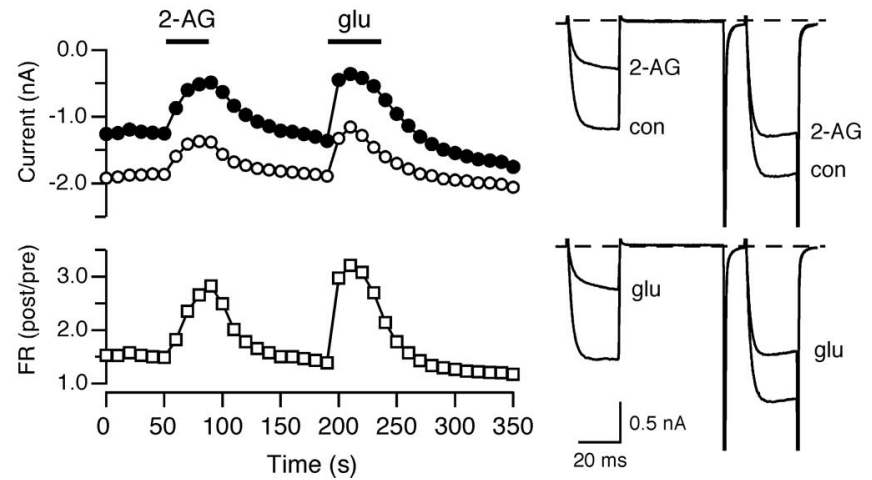

Figure 2. Construction of an eCB synthesis/detection system within a single sympathetic neuron. $A$, Proposed model system for mGluR5a-mediated 2-AG generation/detection in a single neuron. Colored symbols ( $m G l u R 5 a, D A G L \alpha$, Homer $2 b$, and $C_{1} R$ ) represent components heterologously expressed by intranuclear microinjection of $c D N A$ vectors. Black and white coded symbols $\left(G_{q} / 11\right.$, $\mathrm{PLC} \beta, \mathrm{G}_{\mathrm{i} / o^{\prime}}, \mathrm{G} \beta \gamma, \mathrm{PIP}_{2}$, and $\left.\mathrm{Ca}_{\mathrm{v}} 2.2\right)$ represent components native to $\mathrm{SCG}$ neurons. $\boldsymbol{B}-\boldsymbol{E}$, Time courses and superimposed current traces of $I_{\mathrm{Ca}}$ amplitude in $\mathrm{SCG}$ neurons expressing $\mathrm{mGluR5a}(\boldsymbol{B})$,

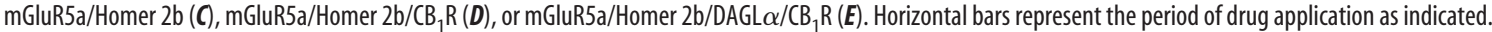

global uncoupling of mGluR5 from intracellular signaling pathways (Kammermeier et al., 2000; Kammermeier and Worley, 2007; Kammermeier, 2008).

The initial attempt at molecular reconstitution of eCB generation/detection is illustrated in Figure 2D. SCG neurons were injected with plasmids encoding mGluR5a/Homer $2 \mathrm{~b} / \mathrm{CB}_{1} \mathrm{R}$ and recorded from the following day. After $60 \mathrm{~s}$ of baseline recording, neurons were superfused with 2-AG $(10 \mu \mathrm{M})$ to determine functional expression of $\mathrm{CB}_{1} \mathrm{R}$. Neurons unresponsive to 2-AG application were excluded from further analyses. Following removal of 2-AG, currents were allowed to recover to baseline amplitude. Approximately $90 \mathrm{~s}$ following cessation of 2-AG application, L-glutamate $(100 \mu \mathrm{M})$ was applied and the prepulse $I_{\mathrm{Ca}}$ amplitude determined. Since Homer $2 \mathrm{~b}$ uncouples mGluR5a from $I_{\mathrm{Ca}}$ inhibition (Fig. 2C), it was expected that robust voltage-dependent $I_{\mathrm{Ca}}$ modulation during L-glutamate application would be indicative of eCB-mediated signaling. Under these conditions (mGluR5a/ Homer $\left.2 \mathrm{~b} / \mathrm{CB}_{1} \mathrm{R}\right)$, L-glutamate application produced a modest and variable (among different neurons) prepulse $I_{\mathrm{Ca}}$ inhibition $(20.5 \pm 3.5 \%, n=23)$. We thus added a cDNA coding for DAGL $\alpha$ to the injected cDNA mixture hypothesizing that an enzyme responsible for 2-AG synthesis was either absent or limiting in SCG neurons. The addition of DAGL $\alpha$ resulted in robust $I_{\mathrm{Ca}}$ inhibition during L-glutamate application (Fig. 2E). Moreover, this modulation of $I_{\mathrm{Ca}}$ was more voltage-dependent $(\mathrm{FR}=2.8)$ when compared with the trace obtained when mGluR5a alone was activated (Fig. $2 B)(F R=1.45)$. These data were consistent with mGluR5-mediated 2-AG biosynthesis, transport, and subsequent activation of $\mathrm{CB}_{1} \mathrm{R}$.
A summary of average $I_{\mathrm{Ca}}$ inhibition by 2-AG and L-glutamate in SCG neurons expressing several different cDNA combinations is depicted in Figure 3. When EGFP alone was expressed, $I_{\mathrm{Ca}}$ inhibition by either 2-AG or L-glutamate was negligible, confirming the absence of functional natively expressed mGluRs or $\mathrm{CB}_{1} \mathrm{R}$ in $\mathrm{SCG}$ neurons. Expression of mGluR5a or $\mathrm{CB}_{1} \mathrm{R}$ produced the expected robust $I_{\mathrm{Ca}}$ modulation when the cognate agonist was applied (Fig. 3, second and third bar set). Expression of mGluR5a/Homer $2 \mathrm{~b}$ blunted the response to L-glutamate and set the baseline for detection of eCB release (Fig. 3, dashed line, filled bars). Combining expression of mGluR5a/Homer $2 \mathrm{~b} / \mathrm{CB}_{1} \mathrm{R}$ provided a hint of eCB production. However, the addition of DAGL $\alpha$ expression resulted in robust L-glutamate $I_{\mathrm{Ca}}$ inhibition that increased the signal-to-noise ratio of the assay. Although L-glutamate-mediated $I_{\mathrm{Ca}}$ inhibition was similar for mGluR5a versus mGluR5a/Homer $2 \mathrm{~b} / \mathrm{DAGL} \alpha / \mathrm{CB}_{1} \mathrm{R}$ expressing neurons ( $49.8 \pm 3.35$ vs $50.5 \pm 2.7 \%$ ), FR (Fig. 3 , checkered bars) was greater for the latter condition ( $2.24 \pm 0.1$ vs $1.75 \pm 0.1)$ thus suggesting a different mechanism of $I_{\mathrm{Ca}}$ inhibition. Hereafter, we will refer to neurons expressing mGluR5a/Homer 2b/DAGL $\alpha /$ $\mathrm{CB}_{1} \mathrm{R}$ as MHDC-expressing neurons.

Subsequent experiments were performed in which one or more elements were deleted from the fully reconstituted system (Fig. 3, lower set of bars). Deletion of either $\mathrm{CB}_{1} \mathrm{R}$ or mGluR5a from the expression mixture ablated or reduced to baseline, respectively, the $I_{\mathrm{Ca}}$ modulation by L-glutamate. These results provide evidence that expression of DAGL $\alpha$ did not impart unexpected properties, such as a change in agonist specificity, on either $\mathrm{CB}_{1} \mathrm{R}$ or mGluR5a. Deletion of Homer $2 \mathrm{~b}$ from the MHDC 


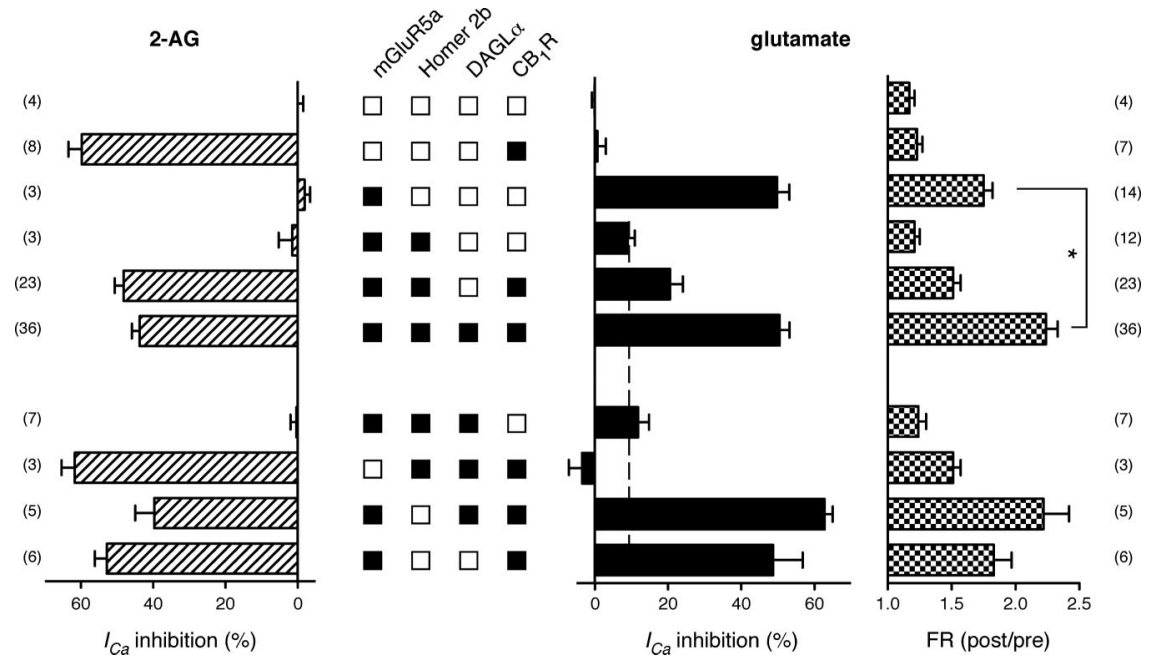

Figure 3. Reconstitution of eCB synthesis/detection system require MHDC expression. Bar graphs represent the mean percentage of prepulse $I_{\mathrm{Ca}}$ inhibition and FR produced by application of either $10 \mu \mathrm{m} 2-\mathrm{AG}$ (left, dashed bars) or $100 \mu \mathrm{m} \mathrm{L-glutamate}$ (right, filled and checkered bars) from SCG neurons expressing the indicated components. The squares between two sets of bar graphs indicate whether a CDNA component was included (filled squares) or excluded (open squares) from the injection mixture. Data are presented as mean \pm SEM. The number of neurons tested is indicated in parentheses on each side of the graph. ${ }^{*} p<0.05$ by one-way ANOVA followed by Tukey's multiple-comparison tests. Statistical significance for other combinations not shown.

$\mathbf{A}^{\mathrm{CB}_{1} \mathrm{R} \text { antagonist }}$

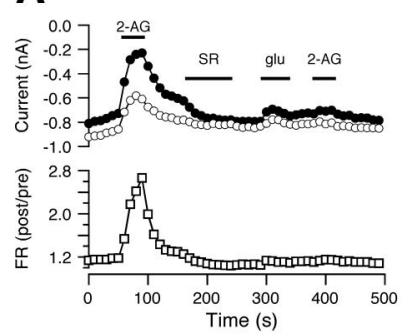

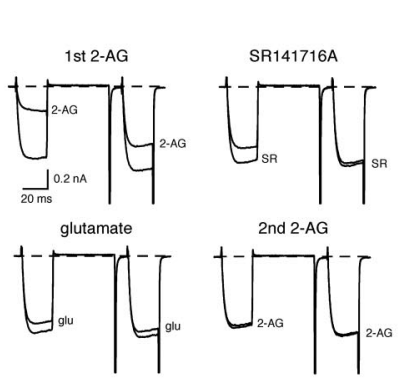

$\mathbf{D}_{\text {PLC innibitors }}$

$\mathbf{C}_{\mathrm{PTX}}$

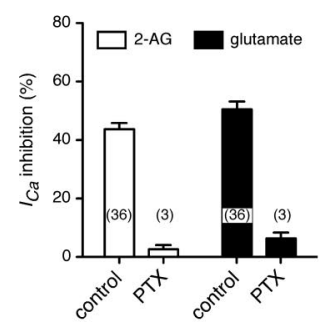

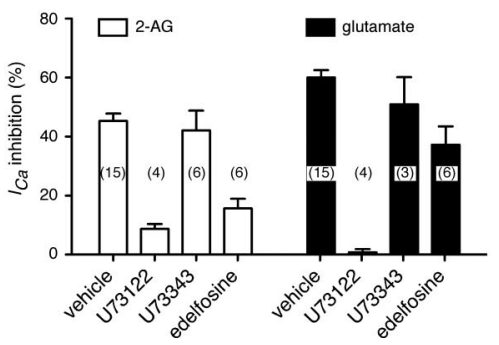

Figure 4. Pharmacology of the MHDC-expressing system. $\boldsymbol{A}$, Time courses of $I_{\mathrm{Ca}_{\mathrm{b}}}$ inhibition (left) and superimposed current traces (right) recorded during application of 2-AG (10 $\mu \mathrm{M}$, first application), the selective $\mathrm{CB}_{1} R$ antagonist SR141716A $(0.1 \mu \mathrm{M})$, L-glutamate (100 $\mu \mathrm{M})$, and 2-AG (second application) from MHDC-expressing SCG neurons. Horizontal bars represent the period of each drug application. $\boldsymbol{B}$, Summary for the mean Ca $_{\text {a }}$ inhibition produced application of 2-AG or L-glutamate before (first column) and after (second and third columns) application of SR141716A. C, Bar graph summarizing the effects of Bordetella pertussis toxin (PTX) pretreatment on the mean / $_{\text {a }}$ inhibition produced by 2-AG (open bars) or L-glutamate (filled bars). D, Bar graph summarizing the effects of vehicle $(0.1 \%$ DMSO), the PLC inhibitor U73122 $(1 \mu \mathrm{M})$, and the "inactive" analog U73343 (1 $\mu \mathrm{M})$ on Ca $_{\text {a }}$ inhibition. Results from another PLC inhibitor, edelfosine (10 $\mu \mathrm{m}$, preincubation for $10 \mathrm{~min}$ at room temperature), are also shown. E, Summary bar graph depicting the effect of the DAG lipase inhibitor tetrahydrolipstatin (THL, $10 \mu \mathrm{m}$ ) on mean Ca $_{\text {a }}$ inhibition by 2-AG (open bars) or L-glutamate (filled bars). Neurons were pretreated with THL for $1 \mathrm{~h}$ before recording.

expression mixture resulted in a large $(62.8 \pm 2.2 \%, n=5)$ voltage-dependent (mean FR $2.2 \pm 0.2, n=5$ ) $I_{\mathrm{Ca}}$ inhibition when L-glutamate was applied. These data were similar to those obtained with the MHDC-expressing neurons. Likewise, expression of just the two GPCRs, mGluR5a and $\mathrm{CB}_{1} \mathrm{R}$, yielded large $I_{\mathrm{Ca}}$ inhibition by both agonists. In the latter two experimental condi-
B Summary

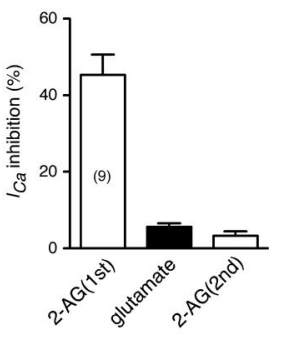

E

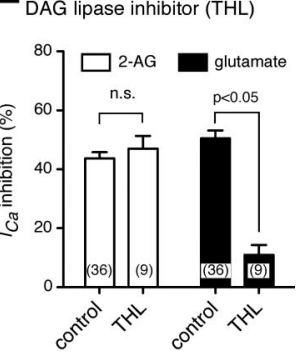

tions, the lack of Homer $2 \mathrm{~b}$ expression made interpretation of the results ambiguous. Although the experiments depicted in Figures 2 and 3 provide expression-based evidence for mGluR5a-mediated eCB signaling cascade, complex multicomponent expression systems are potentially confounded by unanticipated transcription and/or translation interactions. Thus, pharmacological experiments, which occur within an acute time frame, provided important additional validation of the model system.

\section{Pharmacology of the eCB signaling system}

The competitive $\mathrm{CB}_{1} \mathrm{R}$ antagonist SR141716A (100 nM) was applied to MHDC-expressing neurons following application of 2-AG (Fig. 4A). The neuron were subsequently challenged at $300 \mathrm{~s}$ with L-glutamate followed by second exposure to 2-AG. In the neuron illustrated, $I_{\mathrm{Ca}}$ inhibition by L-glutamate following SR141716A exposure was attenuated supporting the notion that $I_{\mathrm{Ca}}$ inhibition under these conditions was mediated by $\mathrm{CB}_{1} \mathrm{R}$ and not mGluR5a. A second challenge with 2-AG established the continued blockade of $\mathrm{CB}_{1} \mathrm{R}$ by SR141716A following washout. Mean prepulse $I_{\mathrm{Ca}}$ inhibitions for nine neurons using this protocol are shown in Figure 4B. SR141716A reduced L-glutamate inhibition of $I_{\mathrm{Ca}}$ to $5.7 \pm 0.8 \%$ compared with $45.5 \pm 3.6 \%$ in the absence of $\mathrm{CB}_{1} \mathrm{R}$ antagonist (see Fig. 3). To assess the selectivity of SR141716A, neurons $(n=9)$ expressing mGluR5a alone (e.g., Fig. $2 B$ ) were exposed to brief applications of L-glutamate separated by $60 \mathrm{~s}$ of SR141716A (100 nM) application (data not shown). Prepulse $I_{\mathrm{Ca}}$ inhibition was $58.4 \pm 4.2$ and $60.9 \pm 3.8 \%$ during the first and second L-glutamate application, respectively, indicating that SR141716A did not block mGluR5a; a prerequisite for meaningful interpretation of these data.

Pretreatment (overnight) of the MHDCexpressing neurons with Bordetella pertussis PTX greatly attenuated both 2-AG and L-glutamate induced $I_{\mathrm{Ca}}$ inhibition $(2.6 \pm$ 1.4 and $6.4 \pm 2 \%$ ) (Fig. $4 C$ ). As only the $\mathrm{CB}_{1} \mathrm{R}$ response was expected to ablated by PTX-treatment (Kammermeier and Ikeda, 1999; Guo and Ikeda, 2004) these data provide further evidence that $I_{\mathrm{Ca}}$ modulation following L-glutamate application in MHDC-expressing neurons was mediated by $\mathrm{CB}_{1} \mathrm{R}$, and hence eCB release, rather than mGluR5a.

A summary of experiments designed to examine the participation of PLC in MHDC-expressing neurons is shown in Figure $4 D$. Several PLC $\beta$ isoforms are native to SCG neurons (Haley et al., 2000) and PLC $\beta$ activity is believed to initiate events leading 
to 2-AG production. The experimental protocol was identical to that illustrated in Figure $2 E$ with the exception that neurons were incubated for $10 \mathrm{~min}$ before recording with putative PLC inhibitors or vehicle (0.1\% DMSO). The commonly used aminosteriod PLC inhibitor U73122 $(1 \mu \mathrm{M})$ ablated $(0.8 \pm 1.1 \%, n=4)$ L-glutamate-mediated $I_{\mathrm{Ca}}$ inhibition (Fig. $4 C$, second filled bar) as anticipated, but also, unexpectedly, greatly attenuated $(8.7 \pm 1.7 \%, n=4) 2-\mathrm{AG}$ effects (second open bar). The "inactive" control analog, U73343, was without effect on either 2-AG- or L-glutamate-mediated $I_{\mathrm{Ca}}$ inhibition. Although not studied further, these results are entirely consistent with previous findings (Horowitz et al., 2005) showing that U73122 (but not U73343), in addition to inhibiting PLC, alkylates $\mathrm{G}_{\mathrm{i} / \mathrm{o}} \mathrm{G}$-proteins thereby blocking the effects of GPCRs that couple through these pathways (e.g., $C_{1} R$ ). Hashimotodani et al. (2008) also documented effects of $\mathrm{U} 73122$ on $\mathrm{CB}_{1} \mathrm{R}$-mediated presynaptic actions that were presumed to be independent of PLC. Conversely, there are reports demonstrating rather specific actions of U73122 within this context (Liu et al., 2008; Marinelli et al., 2008). Regardless, such "off target" actions raise serious questions concerning the validity of using U73122 as a pharmacological tool for establishing the participation of PLC in complex signaling pathways. Combined with similar findings in the literature, our results suggest that the popularity of U73122 is unwarranted. We also tried edelfosine (Et-18- $\left.\mathrm{OCH}_{3}\right)$, an ether lipid analog inhibitor of PLC (Horowitz et al., 2005). Although preincubation (10 min at room temperature) of the neurons with edelfosine $(10 \mu \mathrm{M})$ reduced L-glutamate-mediated $I_{\mathrm{Ca}}$ inhibition $(37.2 \pm 6.2$ vs $60.0 \pm 2.5 \%$ for vehicle; $p<0.05$ Dunnett's multiple-comparison test), 2 -AG mediated inhibition was also substantially reduced ( $15.7 \pm 3.3$ vs $45.3 \pm 2.6 \%$ for vehicle) (Fig. $4 C)$. The latter effects were unexpected and confounded meaningful interpretation of these data. These results underscore the need for more specific and properly validated PLC inhibitors.

Our previous results (Figs. 2 and 3) show that expression of DAGL $\alpha$ augments eCB production in MHDC-expressing neurons. We thus tested whether DAG lipase inhibitors impacted putative $\mathrm{eCB}$ production in this system. Although RHC-80267 is widely used as a DAG lipase inhibitor, confounding nonspecific effects have been reported recently (Hashimotodani et al., 2008). We therefore used tetrahydrolipstatin (THL), a more potent inhibitor of DAG lipase (Lee et al., 1995) than RHC-80267. MHDCexpressing neurons were incubated with THL $(10 \mu \mathrm{M})$ for $1 \mathrm{~h}$ at $37^{\circ} \mathrm{C}$ before recording the effects of 2-AG and L-glutamate application. THL pretreatment had no significant effect of 2-AG mediated $I_{\mathrm{Ca}}$ inhibition (Fig. $4 E$, open bars) while greatly reducing the effects of L-glutamate $(11.0 \pm 3.3 \%, n=9)$. Although these results are consistent with a requirement for DAG lipase in this system, a direct effect
B 2-AG washout $\tau$

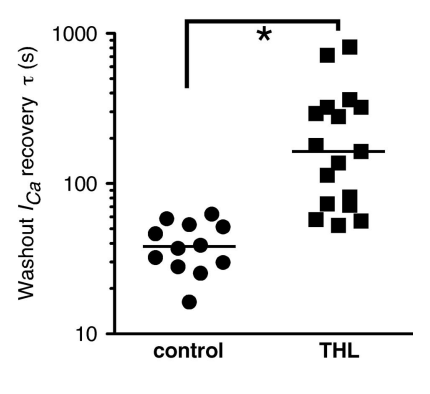

Figure 5. The washout of 2-AG was retarded in THL-treated MHDC-expressing neurons. $A$, Time course of Ca $_{\text {a }}$ inhibition (left) and superimposed current traces (right) recorded during application of 2-AG $(10 \mu \mathrm{M})$ or L-glutamate $(100 \mu \mathrm{M})$ in THL-treated MHDCtial function to control (filled circles) and THL preincubated (filled squares) MHDC-expressing SCG neurons. Solid line represents the

A DAGL activity in SCG neurons

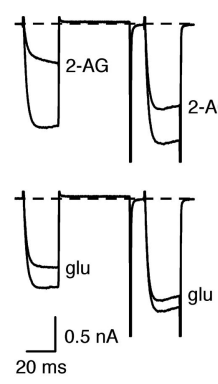

Figure 6. A subset of $S C G$ neurons natively expresses DAGL $\alpha$. A, Scatter plot graph depicting $I_{C_{a}}$ inhibition following application of ean and SD are shown * indicates that variances were significantly different $(p<0.05 \cdot F$ test) $B, R T-P C R$ analysis of $P$ PNA encoding DAGL $\alpha$ from whole SCG ganglia (left) or single dissociated SCG neurons (right). The resultant PCR products were sepaated and visualized on $1.5 \%$ agarose gel. Left, mw: Molecular mass marker, set \#1 and set \#2 indicate RT-PCR products generated respectively. Right, Lanes $1-6$ represent single cell RT-PCR products from $\mathrm{h} / \mathrm{r}$ DAGL $\alpha$ (517 bp) primer pairs. The single cell RT-PCR was multiplexed with a $\beta$-actin primer set (predicted product $=982 \mathrm{bp}$ ) to establish successful neuron isolation.

of THL on mGluR5a would weaken this interpretation. To examine this possibility, mGluR5a-expressing neurons, in the absence of Homer 2 b (e.g., Fig. $2 B$ ), were treated with THL as described above. Application of L-glutamate produced mean $I_{\mathrm{Ca}}$ inhibition of $43.3 \pm 3.1 \%(n=5)$, a value similar to that observed in the absence of THL pretreatment ( $40.5 \pm 6.7 \%, n=7)$. Thus, THL was devoid of significant mGluR5a antagonist effects under these conditions. The results also suggest that DAG lipase does not participate in $I_{\mathrm{Ca}}$ modulation mediated directly by mGluR5a.

In addition to attenuating L-glutamate-mediated $I_{\mathrm{Ca}}$ inhibition, the washout of $2-\mathrm{AG}$ mediated $I_{\mathrm{Ca}}$ inhibition was retarded in THL-treated neurons. Figure $5 \mathrm{~A}$ illustrates a representative $I_{\mathrm{Ca}}$ time course from a MHDC-expressing neuron treated with THL. $I_{\mathrm{Ca}}$ inhibition by 2-AG was voltage-dependent as indicated by the large increase in FR (open squares) and signature changes in current trajectory (Fig. 5A, top traces). However, the prepulse $I_{\mathrm{Ca}}$ amplitude (filled circles) returned slowly to baseline when compared with untreated neurons (compare Figs. $5 A$ and $2 E$ ). This kinetic alteration was quantified by fitting a single exponential function to the 2-AG washout phase. The decay time constants 
$(\tau)$ for untreated neurons were grouped around a median of $38 \mathrm{~s}$ (range 16-63s; $n=12$ ), while the those of THL-treated neurons varied over a much wider range (range $52-811 \mathrm{~s} ; n=17$ ) with a median $\tau$ of $164 \mathrm{~s}$ (Fig. $5 B)$ ( $p<0.05$ Mann-Whitney test). The mechanism underlying this difference is unclear although inhibition of a 2-AG metabolizing enzyme by THL is a possibility. In this regard, THL is a broad-spectrum lipase inhibitor (Borgström, 1988) and thus lipase targets other than DAGL $\alpha$ are plausible.

\section{DAG lipase in SCG neurons}

We inferred the presence of a natively expressed DAGL $\alpha$-like protein in SCG neurons from the analyses depicted in Figure $6 \mathrm{~A}$ in which $I_{\mathrm{Ca}}$ inhibition produced by L-glutamate application for individual neurons are plotted. In neurons expressing mGluR5a/ Homer $2 \mathrm{~b} / \mathrm{CB}_{1} \mathrm{R}$ (open squares), there was a large increase in variance ( $\mathrm{SD}$ are plotted here rather than SEM) when compared with the control condition in which $\mathrm{CB}_{1} \mathrm{R}$ cDNA was omitted (open triangles). Pretreatment with THL (filled squares) reduced the variance ( $p<0.05 F$ test, when compared with untreated neurons) toward control levels. These results raise the possibility that DAGL $\alpha$ or a similar protein is native to a subpopulation of SCG neurons.

To address this possibility, we examined expression of DAGL $\alpha$ mRNA using single cell RT-PCR analysis (Fig. 6). As a first step, we performed RT-PCR using two sets of DAGL $\alpha$ primer sets on mRNA isolated from whole SCG (Fig. 6B, left). Gel electrophoresis showed bands compatible with the predicted product size of the two primer sets ( 365 and $517 \mathrm{bp}$, respectively). We then performed RT-PCR analysis on mRNA from single dissociated SCG neurons. The PCR was multiplexed with $\beta$-actin primers to establish successful neuron isolation. Of the neurons tested, 9 of 16 reactions produced a band of the expected size for DAGL $\alpha$ (Fig. $6 B$, right). Together, these results indicate that a subset of SCG neurons express DAGL $\alpha$ and this expression may account for modest (and highly variable) eCB production in the absence of exogenously expressed DAGL $\alpha$. The results are consistent with a recent report of DAGL $\alpha$ expression in rat SCG neurons using in situ hybridization and immunostaining (Liu et al., 2008).

Effect of $\left(\mathrm{DiC}_{8}\right)-\mathrm{PIP}_{2}$ and $\mathrm{Ca}^{2+}$ buffers in the pipette solution Gamper et al. (2004) reported that PIP $_{2}$ depletion following muscarinic AChR stimulation underlies voltage-independent modulation of $\mathrm{N}$-type $\mathrm{Ca}^{2+}$ channels in SCG neurons. We therefore recorded from $\mathrm{MHDC}$-expressing neurons using a pipette solution containing $200 \mu \mathrm{M}(\mathrm{DiC})_{8}-\mathrm{PIP}_{2}$, a short chain water-soluble $\mathrm{PIP}_{2}$ analog that substitutes for $\mathrm{PIP}_{2}$ at $\mathrm{N}$-type channels. The pipette solution was sonicated before each recording to disperse the phosphoinositide. Intracellular dialysis with $(\mathrm{DiC})_{8}-\mathrm{PIP}_{2}$ containing pipette solution had little effect on mean $I_{\mathrm{Ca}}$ inhibition by either 2-AG or L-glutamate (Fig. 7). While we assume that $\mathrm{PIP}_{2}$ hydrolysis occurs during mGluR5a stimulation to provide substrate (i.e., DAG) for 2-AG production, these results argue that extensive $\mathrm{PIP}_{2}$ depletion around $\mathrm{N}$-type $\mathrm{Ca}^{2+}$ channels does not occur in this expression system. It has also been reported that mAChR stimulation liberates arachidonic acid (AA) from membrane phospholipids, which subsequently modulates both L- and $\mathrm{N}$-type channels in SCG neurons (Liu et al., 2008). Metabolism of 2-AG also releases AA and glycerol as hydrolysis products. Because all experiment was done in the presence of $0.5 \mathrm{mg} / \mathrm{ml}$ fatty acid free BSA, a protein that binds AA thereby preventing effects

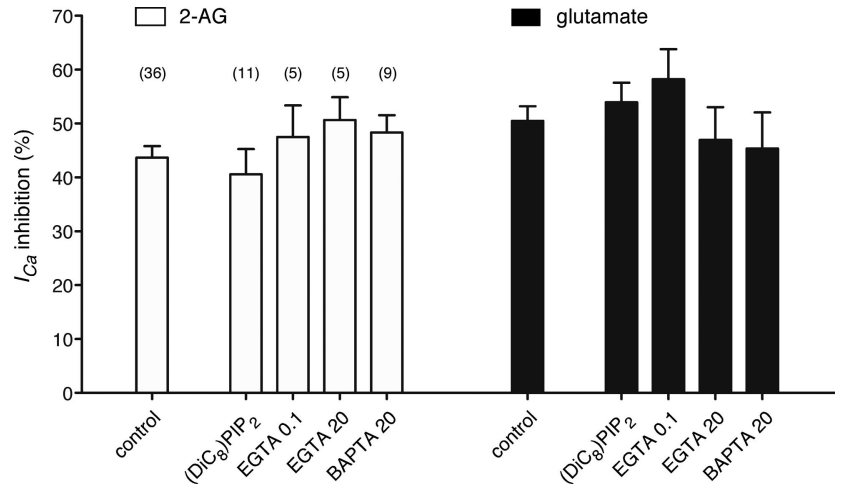

Figure 7. Effect of $\left(\mathrm{DiC}_{8}\right)-\mathrm{PIP}_{2}$ or $\mathrm{Ca}^{2+}$ buffers in the pipette solution. Bar graph depicting the mean Ia $_{\text {a }}$ inhibition by either 2-AG (10 $\mu \mathrm{M}$, open bars) or L-glutamate (100 $\mu \mathrm{M}$, filled bars) from MHDC-expressing SCG neurons. First column of the each open and filled bar groups indicate control using standard pipette solution (see the Materials and Methods). To substitute for $\mathrm{PIP}_{2}$ depletion during mGluR5a stimulation, $200 \mu \mathrm{M}\left(\mathrm{DiC}_{8}\right) \mathrm{PIP}_{2}$ was included in the pipette solution (second column). The last three columns represent the average $I_{\mathrm{Ca}}$ inhibition with the different $\mathrm{Ca}^{2+}$ buffering capacity in the pipette solution from low (EGTA $0.1 \mathrm{~mm}$ ) to high (EGTA $20 \mathrm{~mm}$ or BAPTA $20 \mathrm{~mm}$ ). Data are presented as mean \pm SEM, and numbers in parentheses indicate the number of neurons tested.

on $\mathrm{Ca}^{2+}$ channels, we conclude that AA did not substantially contribute to $I_{\mathrm{Ca}}$ modulation in this system.

We also examined the effect of altering the pipette solution $\mathrm{Ca}^{2+}$ buffering capacity (Fig. 7) as several components of the 2-AG biosynthetic pathway, including PLC $\beta$ and DAGL $\alpha$, are reported to be sensitive to intracellular $\left[\mathrm{Ca}^{2+}\right]$. The standard pipette solution used throughout these studies contained $11 \mathrm{~mm}$ EGTA/1 $\mathrm{mM} \mathrm{CaCl}_{2}$ which provides for moderate buffering capacity at $\sim 10-30 \mathrm{nM}\left[\mathrm{Ca}^{2+}\right]$. Three additional buffering conditions were tested on MHDC-expressing neurons. The first, $0.1 \mathrm{~mm}$ EGTA with no added $\mathrm{CaCl}_{2}$, was designed to provide minimal buffering capacity while still chelating contaminating $\mathrm{Ca}^{2+}$ arising from glass or reagents. Conversely, the second and third conditions, $20 \mathrm{~mm}$ EGTA or BAPTA (without added $\mathrm{CaCl}_{2}$ ), were designed to buffer $\mathrm{Ca}^{2+}$ to levels $<10^{-8} \mathrm{M}$ with high capacity. BAPTA has the advantage of more rapid $\mathrm{Ca}^{2+}$ binding kinetics and thus offers improved temporal control of local $\left[\mathrm{Ca}^{2+}\right]$ near areas of influx (Marty and Neher, 1985). None of these alterations in $\mathrm{Ca}^{2+}$ buffering significantly impacted $I_{\mathrm{Ca}}$ inhibition by either 2-AG or L-glutamate (Fig. 7, $p>0.05$ when compared with control, ANOVA followed by Dunnett's multiple-comparison test). Thus, eCB production in this system is neither enhanced by relaxing $\mathrm{Ca}^{2+}$ buffering toward more physiological levels nor dependent on large increases in cytosolic $\left[\mathrm{Ca}^{2+}\right]$.

\section{Cytosolic C terminus of DAGL $\alpha$ contributes to the 2-AG signaling cascade}

DAGL $\alpha$ is comprised of an $\mathrm{N}$ terminus containing four (putative) transmembrane spanning domains and an extended cytosolic $\mathrm{C}$ terminus containing an $\alpha / \beta$ hydrolase domain and a validated Homer protein binding motif (Bisogno et al., 2003; Jung et al., 2007). To better understand how each region contributed to the responses seen in MHDC-expressing neurons, we made cDNA constructs encoding each terminus (Fig. 8A). Expression of either $\mathrm{N}$ or $\mathrm{C}$ terminus in place of the full-length DAGL $\alpha$ had no impact on $I_{\mathrm{Ca}}$ inhibition by 2 -AG (Fig. $8 \mathrm{~B}$, open bars). Conversely, expression of the $\mathrm{N}$ terminus, but not the $\mathrm{C}$ terminus, significantly attenuated $I_{\mathrm{Ca}}$ inhibition when compared with the full-length DAGL $\alpha$ (Fig. $8 B$, filled bars). These results are consistent with lipase activity being contained within the $\mathrm{C}$ 


\section{A DAGL $\alpha$ schematic}

Full length

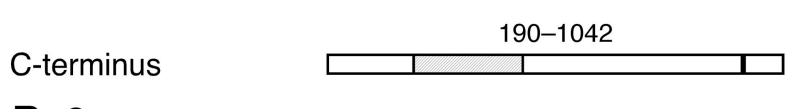

B Summary

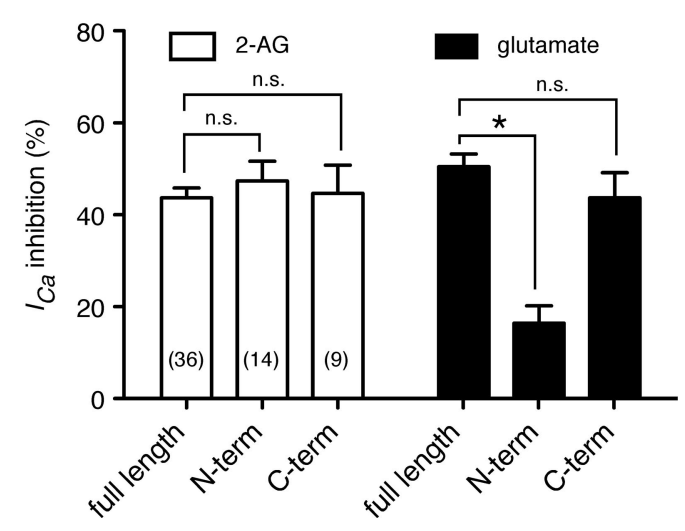

Figure 8. Structure/function of DAGL $\alpha$. A, Schematic representation of full-length DAGL $\alpha$ (upper), the $\mathrm{N}$ terminus (middle), and the ( terminus (bottom). DAGL $\alpha$ is comprised of an $\mathrm{N}$ terminus containing four (putative) transmembrane spanning domains (filled boxes) and extended long cytosolic C terminus, which contains an $\alpha / \beta$-hydrolase domain (dashed box) and validated Homer protein binding motif (black). $\boldsymbol{B}$, Summary of the mean I $_{\mathrm{Ca}}$ inhibition produced by $10 \mu \mathrm{m}$ 2-AG (open bars) or $100 \mu \mathrm{m} \mathrm{L-glutamate} \mathrm{(filled} \mathrm{bars)} \mathrm{from} \mathrm{SCG} \mathrm{neurons} \mathrm{expressing}$ mGluR5a/Homer 2b/CB R with full-length DAGL $\alpha$ (control) or DAGL $\alpha-\Delta C$ (N-term) or $N \Delta$ DAGL $\alpha$ (C-term). Data are presented as mean \pm SEM and numbers in parentheses indicate the number of neurons tested. ${ }^{*} p<0.05$ one-way ANOVA followed by Dunnett's multiplecomparison test with control (full length).

terminus. Although the $\mathrm{N}$ terminus is believed to localize the enzyme to the plasma membrane, these data indicate that this property is dispensable, at least in terms of L-glutamate-mediated $I_{\mathrm{Ca}}$ inhibition.

\section{Discussion}

\section{Validating a model for receptor-mediated eCB signaling} cascade reconstituted in a single neuron

Three principal classes of retrograde eCB signaling in central neurons have been identified based on a requirement for: (1) increases in intracellular $\left[\mathrm{Ca}^{2+}\right]$, termed CaER; (2) activation of a $\mathrm{G}_{\mathrm{q} / 11}$-coupled GPCR, termed basal RER; or (3) concomitant or sequential increase in intracellular $\left[\mathrm{Ca}^{2+}\right]$ and activation of GPCR, termed $\mathrm{Ca}^{2+}$-RER (Kano et al., 2009). We elected to pursue the second category as $I_{\mathrm{Ca}}$ modulation following heterologous expression of mGluR5a and $\mathrm{CB}_{1} \mathrm{R}$ in $\mathrm{SCG}$ neurons has been previously studied (Ikeda et al., 1995; Kammermeier and Ikeda, 1999; Guo and Ikeda, 2004). The targeted endpoint was a functional trans-activation of $\mathrm{CB}_{1} \mathrm{R}$ following activation of mGluR5a with L-glutamate.

Several lines of evidence support the notion that $I_{\mathrm{Ca}}$ modulation during L-glutamate application in MHDC-expressing neurons arises from acute 2-AG biosynthesis and subsequent activation of $\mathrm{CB}_{1} \mathrm{R}$ (Fig. $2 \mathrm{~A}$ ). First, the response was greatly enhanced by expression of DAGL $\alpha$. Second, $I_{\mathrm{Ca}}$ inhibition by L-glutamate was voltage-dependent with a FR greater than that measured when mGluR5a alone was expressed. Third, excluding or blocking $\mathrm{CB}_{1} \mathrm{R}$ reduced $I_{\mathrm{Ca}}$ modulation to near baseline (10\% inhibition). Fourth, PTX pretreatment blocked nearly all of the L-glutamate modulation. Fifth, THL blocked L-glutamatemediated $I_{\mathrm{Ca}}$ modulation while having negligible effect on modulation produced by direct $\mathrm{CB}_{1} \mathrm{R}$ or mGluR5a activation. Together, these results address three competing hypotheses. First, mGluR5a could overcome the influence of coexpressed Homer $2 b$ through changes in expression stoichiometry that arise from transcriptional or translational competition. Inhibition by SR141617A and THL, however, argue against this explanation as neither $\mathrm{CB}_{1} \mathrm{R}$ or DAGL $\alpha$ are required for direct mGluR5a modulation of $I_{\mathrm{Ca}}$. Second, a direct transactivation of $\mathrm{CB}_{1} \mathrm{R}$ by mGluR5a might occur in a manner analogous to the recently described mGluR2-5 $\mathrm{HT}_{2 \mathrm{~A}}$ heterodimer. The participation of DAGL $\alpha$, however, as deduced from both genetic and pharmacological experiments, is supportive of an eCB-dependent mechanism rather than direct transactivation via interacting protein domains. Credible evidence for PLC participation would bolster this argument but, unfortunately, interpretation of the U73122 and edelfosine experiments was confounded by nonspecific effects. Third, a signaling pathway that produces arachidonic acid as an intracellular N-type $\mathrm{Ca}^{2+}$ channel inhibitor has been proposed. Although sharing common signaling components, i.e., GPCR, $\mathrm{G}_{\mathrm{q} / 11}$, PLC, and DAG lipase, the requirement for $\mathrm{CB}_{1} \mathrm{R}$, insensitivity to BSA-containing solution, and voltage dependence of $I_{\mathrm{Ca}}$ modulation differentiates the phenomenon seen here from that documented for $\mathrm{M}_{1} \mathrm{mAChR}$-mediated $I_{\mathrm{Ca}}$ modulation (Liu et al., 2004).

\section{Comparison with native synaptic and autocrine systems}

The $I_{\mathrm{Ca}}$ modulation evoked by L-glutamate application in MHDC-expressing SCG neurons share properties with a general class of short-term synaptic depression mediated by Group I

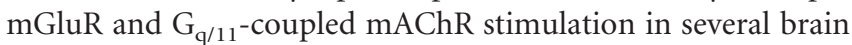
regions (Maejima et al., 2001; Kim et al., 2002; Galante and Diana, 2004; Neu et al., 2007). There properties include attenuation of response following antagonism of PLC, DAG lipase, or $\mathrm{CB}_{1} \mathrm{R}$ but little or no effect of buffering intracellular $\mathrm{Ca}^{2+}$ with high concentration of BAPTA or EGTA. Thus, the single neuron system appears to faithfully mimic receptor-mediated retrograde eCB depression of synaptic transmission in nearly all respects. Whether MHDC-expressing neurons can serve as a model for CaER or $\mathrm{Ca}^{2+}$-RER forms of short-term synaptic depression remains to be investigated.

MHDC-expressing neurons are essentially an autocrine system in which 2-AG transport and signaling occur within the same cell. A similar phenomenon has been described in layer V lowthreshold spiking interneurons of the rat somatosensory cortex in which neurons are hyperpolarized by 2-AG activating $\mathrm{CB}_{1} \mathrm{R}$ coupled to GIRK-type $\mathrm{K}^{+}$channels. The response requires an increase in intracellular $\mathrm{Ca}^{2+}$ and lasts for several minutes (Bacci et al., 2004). Hippocampal neurons cultured to form autapses also display an autocrine form of eCB-mediated synaptic depression (Straiker and Mackie, 2007). The $\mathrm{Ca}^{2+}$ sensitivity of this response in unknown since buffering intracellular $\mathrm{Ca}^{2+}$ would interfere with synaptic transmission. The lack of reported autocrine response in native systems, at least in terms of synaptic transmission, is consistent with the spatial separation of $\mathrm{CB}_{1} \mathrm{R}$ and the receptors and enzymes involved in 2-AG mobilization (Hájos et al., 2004; Yoshida et al., 2006). 


\section{Utility for exploring mechanisms of 2-AG transport}

We examined the hypothesis that the putative membrane spanning domain of DAGL $\alpha$ might comprise a transporter for newly synthesized 2-AG. Although we are unaware of data supporting this idea, the four membrane spanning domains in the $\mathrm{N}$ terminus seem well positioned to serve this function. Our results, however, did not support this hypothesis. Structural/function studies indicate a requirement for the enzymatic region of DAGL $\alpha$ but not the TM domains (Fig. $8 B$ ). Thus, the question of whether a transport protein is required remains unanswered. It is possible that 2-AG generated by DAGL $\alpha$ remains buried within the inner leaflet of the plasma membrane sequestered from degradative enzymes. However, sufficient evidence exists for an $\mathrm{eCB}$ membrane transporter that further investigation is warranted (Hájos et al., 2004; McFarland and Barker, 2004; Ronesi et al., 2004; Yoshida et al., 2006; Adermark and Lovinger, 2007). The genetic malleability of the system makes exploration of candidate proteins feasible.

We have not extensively tested whether the CaER, $\mathrm{Ca}^{2+}-\mathrm{RER}$, or additional forms of eCB-mediated short-term synaptic depression are recapitulated in this system. It is unclear whether the pathways are comprised of discrete or common signaling elements. For example, a form of $\mathrm{Ca}^{2+}-\mathrm{RER}$ in primary cultures of corticostriatal and hippocampal slices from early postnatal rats appeared to use DAGL $\beta$ rather than DAGL $\alpha$ (Jung et al., 2005). Investigating how DAGL $\beta$ influences the $2-A G$ signaling cascade in this system simply requires substituting cDNA in the expression mixture. In the same vein, we have only tested Homer $2 \mathrm{~b}$ in our current experiments and it is possible that substituting different Homer isoforms will provide new information. We also anticipate that $\mathrm{CB}_{1} \mathrm{R}$-coupling of GIRK-type $\mathrm{K}^{+}$channels may provide improved temporal resolution of 2-AG transport (Jeong and Ikeda, 2001).

In summary, we have molecularly constructed a reduced model neuronal system that recapitulates most of the important characteristics of retrograde receptor-mediated eCB signaling cascade in the CNS. The system enables facile exploration of various proteins that contribute to this widespread signaling pathway.

\section{References}

Adermark L, Lovinger DM (2007) Retrograde endocannabinoid signaling at striatal synapses requires a regulated postsynaptic release step. Proc Natl Acad Sci U S A 104:20564-20569.

Bacci A, Huguenard JR, Prince DA (2004) Long-lasting self-inhibition of neocortical interneurons mediated by endocannabinoids. Nature 431:312-316.

Bisogno T, Howell F, Williams G, Minassi A, Cascio MG, Ligresti A, Matias I, Schiano-Moriello A, Paul P, Williams EJ, Gangadharan U, Hobbs C, Di Marzo V, Doherty P (2003) Cloning of the first sn1-DAG lipases points to the spatial and temporal regulation of endocannabinoid signaling in the brain. J Cell Biol 163:463-468.

Blankman JL, Simon GM, Cravatt BF (2007) A comprehensive profile of brain enzymes that hydrolyze the endocannabinoid 2-arachidonoylglycerol. Chem Biol 14:1347-1356

Borgström B (1988) Mode of action of tetrahydrolipstatin: a derivative of the naturally occurring lipase inhibitor lipstatin. Biochim Biophys Acta 962:308-316.

Chevaleyre V, Takahashi KA, Castillo PE (2006) Endocannabinoidmediated synaptic plasticity in the CNS. Annu Rev Neurosci 29:37-76.

Delmas P, Abogadie FC, Dayrell M, Haley JE, Milligan G, Caulfield MP, Brown DA, Buckley NJ (1998) G-proteins and G-protein subunits mediating cholinergic inhibition of $\mathrm{N}$-type calcium currents in sympathetic neurons. Eur J Neurosci 10:1654-1666.

Elmslie KS, Zhou W, Jones SW (1990) LHRH and GTP- $\gamma$-S modify calcium current activation in bullfrog sympathetic neurons. Neuron 5:75-80.
Galante M, Diana MA (2004) Group I metabotropic glutamate receptors inhibit GABA release at interneuron-Purkinje cell synapses through endocannabinoid production. J Neurosci 24:4865-4874.

Gamper N, Reznikov V, Yamada Y, Yang J, Shapiro MS (2004) Phosphatidylinositol 4,5-bisphosphate signals underlie receptor-specific $\mathrm{G}_{\mathrm{q} / 11^{-}}$ mediated modulation of N-type $\mathrm{Ca}^{2+}$ channels. J Neurosci 24:1098010992.

Guo J, Ikeda SR (2004) Endocannabinoids modulate N-type calcium channels and G-protein-coupled inwardly rectifying potassium channels via CB1 cannabinoid receptors heterologously expressed in mammalian neurons. Mol Pharmacol 65:665-674.

Hájos N, Kathuria S, Dinh T, Piomelli D, Freund TF (2004) Endocannabinoid transport tightly controls 2-arachidonoyl glycerol actions in the hippocampus: effects of low temperature and the transport inhibitor AM404. Eur J Neurosci 19:2991-2996.

Haley JE, Abogadie FC, Fernandez-Fernandez JM, Dayrell M, Vallis Y, Buckley NJ, Brown DA (2000) Bradykinin, but not muscarinic, inhibition of M-current in rat sympathetic ganglion neurons involves phospholipase C- $\beta 4$. J Neurosci 20:RC105.

Hamill OP, Marty A, Neher E, Sakmann B, Sigworth FJ (1981) Improved patch-clamp techniques for high-resolution current recording from cells and cell-free membrane patches. Pflugers Arch 391:85-100.

Hashimotodani Y, Ohno-Shosaku T, Maejima T, Fukami K, Kano M (2008) Pharmacological evidence for the involvement of diacylglycerol lipase in depolarization-induced endocanabinoid release. Neuropharmacology 54:58-67.

Herlitze S, Garcia DE, Mackie K, Hille B, Scheuer T, Catterall WA (1996) Modulation of $\mathrm{Ca}^{2+}$ channels by G-protein $\beta \gamma$ subunits. Nature 380:258-262.

Horowitz LF, Hirdes W, Suh BC, Hilgemann DW, Mackie K, Hille B (2005) Phospholipase $\mathrm{C}$ in living cells: activation, inhibition, $\mathrm{Ca}^{2+}$ requirement, and regulation of M current. J Gen Physiol 126:243-262.

Ikeda SR (1991) Double-pulse calcium channel current facilitation in adult rat sympathetic neurones. J Physiol 439:181-214.

Ikeda SR (1996) Voltage-dependent modulation of N-type calcium channels by G-protein $\beta \gamma$ subunits. Nature 380:255-258.

Ikeda SR (2004) Expression of G-protein signaling components in adult mammalian neurons by microinjection. Methods Mol Biol 259:167-181.

Ikeda SR, Dunlap K (1999) Voltage-dependent modulation of N-type calcium channels: role of G protein subunits. Adv Second Messenger Phosphoprotein Res 33:131-151.

Ikeda SR, Jeong SW (2004) Use of RGS-insensitive G $\alpha$ subunits to study endogenous RGS protein action on G-protein modulation of N-type calcium channels in sympathetic neurons. Methods Enzymol 389:170-189.

Ikeda SR, Lovinger DM, McCool BA, Lewis DL (1995) Heterologous expression of metabotropic glutamate receptors in adult rat sympathetic neurons: subtype-specific coupling to ion channels. Neuron 14:1029-1038.

Jeong SW, Ikeda SR (2001) Differential regulation of G protein-gated inwardly rectifying $\mathrm{K}^{+}$channel kinetics by distinct domains of RGS8 J Physiol 535:335-347.

Jung KM, Mangieri R, Stapleton C, Kim J, Fegley D, Wallace M, Mackie K, Piomelli D (2005) Stimulation of endocannabinoid formation in brain slice cultures through activation of group I metabotropic glutamate receptors. Mol Pharmacol 68:1196-1202.

Jung KM, Astarita G, Zhu C, Wallace M, Mackie K, Piomelli D (2007) A key role for diacylglycerol lipase-alpha in metabotropic glutamate receptordependent endocannabinoid mobilization. Mol Pharmacol 72:612-621.

Kammermeier PJ (2008) Endogenous homer proteins regulate metabotropic glutamate receptor signaling in neurons. J Neurosci 28:8560-8567.

Kammermeier PJ, Ikeda SR (1999) Expression of RGS2 alters the coupling of metabotropic glutamate receptor 1a to M-type $\mathrm{K}^{+}$and N-type $\mathrm{Ca}^{2+}$ channels. Neuron 22:819-829.

Kammermeier PJ, Worley PF (2007) Homer la uncouples metabotropic glutamate receptor 5 from postsynaptic effectors. Proc Natl Acad Sci U S A 104:6055-6060.

Kammermeier PJ, Xiao B, Tu JC, Worley PF, Ikeda SR (2000) Homer proteins regulate coupling of group I metabotropic glutamate receptors to N-type calcium and M-type potassium channels. J Neurosci 20:7238-7245.

Kammermeier PJ, Davis MI, Ikeda SR (2003) Specificity of metabotropic glutamate receptor 2 coupling to G proteins. Mol Pharmacol 63:183-191. 
Kano M, Ohno-Shosaku T, Hashimotodani Y, Uchigashima M, Watanabe M (2009) Endocannabinoid-mediated control of synaptic transmission. Physiol Rev 89:309-380.

Kim J, Isokawa M, Ledent C, Alger BE (2002) Activation of muscarinic acetylcholine receptors enhances the release of endogenous cannabinoids in the hippocampus. J Neurosci 22:10182-10191.

Lee MW, Kraemer FB, Severson DL (1995) Characterization of a partially purified diacylglycerol lipase from bovine aorta. Biochim Biophys Acta 1254:311-318.

Lin Z, Harris C, Lipscombe D (1996) The molecular identity of Ca channel $\alpha_{1}$-subunits expressed in rat sympathetic neurons. J Mol Neurosci 7:257-267.

Lin Z, Haus S, Edgerton J, Lipscombe D (1997) Identification of functionally distinct isoforms of the $\mathrm{N}$-type $\mathrm{Ca}^{2+}$ channel in rat sympathetic ganglia and brain. Neuron 18:153-166.

Liu L, Roberts ML, Rittenhouse AR (2004) Phospholipid metabolism is required for M1 muscarinic inhibition of N-type calcium current in sympathetic neurons. Eur Biophys J 33:255-264.

Liu L, Heneghan JF, Michael GJ, Stanish LF, Egertová M, Rittenhouse AR (2008) L- and N-current but not M-current inhibition by M1 muscarinic receptors requires DAG lipase activity. J Cell Physiol 216:91-100.

Lovinger DM (2008) Presynaptic modulation by endocannabinoids. Handb Exp Pharmacol 184:435-477.

Maejima T, Hashimoto K, Yoshida T, Aiba A, Kano M (2001) Presynaptic inhibition caused by retrograde signal from metabotropic glutamate to cannabinoid receptors. Neuron 31:463-475.

Margas W, Sedeek K, Ruiz-Velasco V (2008) Coupling specificity of NOP opioid receptors to pertussis-toxin-sensitive $\mathrm{G} \alpha$ proteins in adult rat stel- late ganglion neurons using small interference RNA. J Neurophysiol 100:1420-1432.

Marinelli S, Pacioni S, Bisogno T, Di Marzo V, Prince DA, Huguenard JR, Bacci A (2008) The endocannabinoid 2-arachidonoylglycerol is responsible for the slow self-inhibition in neocortical interneurons. J Neurosci 28:13532-13541.

Marty A, Neher E (1985) Potassium channels in cultured bovine adrenal chromaffin cells. J Physiol 367:117-141.

McFarland MJ, Barker EL (2004) Anandamide transport. Pharmacol Ther 104:117-135.

Neu A, Földy C, Soltesz I (2007) Postsynaptic origin of CB1-dependent tonic inhibition of GABA release at cholecystokinin-positive basket cell to pyramidal cell synapses in the CA1 region of the rat hippocampus. J Physiol 578:233-247.

Ronesi J, Gerdeman GL, Lovinger DM (2004) Disruption of endocannabinoid release and striatal long-term depression by postsynaptic blockade of endocannabinoid membrane transport. J Neurosci 24:1673-1679.

Straiker A, Mackie K (2007) Metabotropic suppression of excitation in murine autaptic hippocampal neurons. J Physiol 578:773-785.

Wang J, Ueda N (2009) Biology of endocannabinoid synthesis system. Prostaglandins Other Lipid Mediat 89:112-119.

$\mathrm{Xu}$ J, He L, Wu LG (2007) Role of $\mathrm{Ca}^{2+}$ channels in short-term synaptic plasticity. Curr Opin Neurobiol 17:352-359.

Yoshida T, Fukaya M, Uchigashima M, Miura E, Kamiya H, Kano M, Watanabe M (2006) Localization of diacylglycerol lipase- $\alpha$ around postsynaptic spine suggests close proximity between production site of an endocannabinoid, 2-arachidonoyl-glycerol, and presynaptic cannabinoid CB1 receptor. J Neurosci 26:4740-4751. 